10.2478/v10367-012-0018-4

ZBIGNIEW PIETRZYKOWSKI, JANUSZ MAGAJ

Maritime University of Szczecin

\title{
THE PROBLEM OF ROUTE DETERMINATION IN SHIP MOVEMENT IN A RESTRICTED AREA
}

\begin{abstract}
This article focuses on the problem of determining a safe trajectory of a ship proceeding in a restricted area. An algorithm of trajectory choice has been developed, taking into account the parameters of the area, own ship, target ship and other vessels sailing in vicinity. The ship domain has been adopted as a safety criterion. The research results for selected test trials are presented and analyzed. The applicability of the proposed method of trajectory choice in real conditions is considered.
\end{abstract}

\section{Keywords:}

safety of navigation, ship trajectory, restricted area, ship domain, multi-stage control.

\section{INTRODUCTION}

The primary task of the navigator conducting the ship is to assure its safe navigation. The growing intensity of vessel traffic and increased sizes and speeds of vessels call for fast and efficient solutions to collision situations that occur at sea. This necessitates the determination of ship's safe trajectory that will account for binding traffic regulations. An increasingly large amount of information available on board allows to better assess the current navigational situation and, on this basis, to make the right decision. On the other hand too much information may lead to human errors, resulting, inter alia, from difficulties in processing the available data, some of which may not be taken into consideration while a decision is being taken. Systems of automatic determination of ship's safe trajectory may be essentially helpful to the navigator. In open sea navigation, except for restrictions due to vessel traffic and present hydrological and meteorological conditions, there are no constraints while altering the ship's trajectory. In restricted waters navigation, where the route cannot often be chosen freely, it is more difficult to formulate and solve the problem of safe trajectory determination. The difficulties are mainly due to heavier vessel 
traffic, e.g. in port approaches, narrow passages or traffic separation schemes. In such waters local conditions have to be taken into consideration (constraint imposed by one of three dimensions determining the ship's distance to other objects or vessels).

The formulation of and solution to the above problem has to start from defining criteria for the choice of a new trajectory and method's of its determination. Another important factor is its computational complexity. This results from the fact that a solution has to be found in a specific period of time, so that the navigator will be able to make a decision and act in real time.

\section{PROBLEM OF THE SHIP TRAJECTORY CHOICE}

\section{Navigational decisions}

On board navigational decisions concerning ship's safe conduct refer to various time spans. In reference to the choice of ship trajectory, or path, two basic groups can be distinguished:

- strategic - voyage planning based on shipowner's decisions;

- operational — safe steering of the ship where collisions are prevented and avoided.

In both cases general shipping safety is taken into account (safety of navigation, ship, personnel, cargo) as well as economical aspects (time, fuel consumption). In the former case the decision maker has to consider mainly restrictions related to navigational conditions (area, weather conditions, regulations); in the latter case the relevant restrictions are those related to the present navigational situation (area, other vessels, regulations in force). In both cases the trajectory (path) determination requires that certain criteria of choice and existing restrictions should be defined. Taking these restrictions into account allows to determine a set of feasible solutions (trajectories). On the basis of adopted criteria the choice of trajectory is made from all feasible solutions. This problem is often formulated as an optimization problem, with an adequately defined objective function (static optimization) or control quality indicator (dynamic optimization). When operational decisions are made, time is a crucial factor, particularly in situations where a risk of collision exists.

The problem of trajectory choice in operational decisions is mostly considered separately for open sea areas and restricted areas. The restricted area means waters where the waves system generated by the ship moving full ahead is disturbed. Contrary to the open sea, in the restricted area the navigator has no freedom in choosing 
the trajectory and has to comply with safety rules accounting for local conditions (restriction of one of three dimensions determining ship's distance to other vessels). As a rule, the choice of path while a ship is sailing in a restricted area requires that more restrictions should be taken into account, such as land areas, depths and other navigational dangers. In general, criteria for path determination have to be modified, particularly safety criteria (for passing other ships, navigational dangers and marine structures).

\section{Criteria of trajectory choice in a restricted area}

Planning a moving ship's trajectory refers to solving situations of encountering other vessels (targets) and stationary objects in order to pass them safely. The navigator, planning such a manoeuvre, bears in mind the following restrictions (area accessibility, ship's manoeuvrability) and uses certain criteria. These are [8]:

- safety criteria:

- safe distance of passing, overtaking, or crossing target's course,

- safe distance of passing stationary objects: land, navigational dangers;

- criteria derived from regulations in force and good sea practice:

- course alteration, readily apparent to another vessel,

- sufficiently early performance of the manoeuvre,

- manoeuvre recommended by regulations;

- economical criteria: loss of time, distance covered, fuel consumption etc.

Safety criteria are primary ones. While the closest point of approach (CPA) is a common criterion used in open sea areas, it cannot be often used in restricted waters. The restriction imposed by at least one dimension defining the ship's distance to other objects makes the passing of other vessels/objects at a distance assumed as safe $\mathrm{CPA}_{\mathrm{L}}$ difficult.

The criterion of ship domain is an alternative to CPA. Authors propose twoand three-dimensional domains. The two-dimensional domain is an area around the ship that its navigator should keep clear of other vessels and objects [5].

The ship fuzzy domain is an extended domain concept, which allows to distinguish dangerous and safe zones [8]. This is an area around the ship that the navigator should keep clear of other vessels and objects, and the shape and size of this area depend on the assumed level of navigational safety, understood as a degree of membership of a navigational situation to the fuzzy set 'dangerous navigation' [10]. 
The shape and size of ship domain and ship fuzzy domain depend on many factors, which makes its determination difficult. This problem is discussed in a number of publications, e.g. [4, 5, 10, 11, 12, 13, 15, 16].

It should be emphasized that in most cases a domain is assigned to the object for which a safe trajectory is being determined - own ship. In an alternative approach domains can be assigned to targets $[13,14]$. In this case our (own) ship is considered as a point. This also requires that domains are assigned to other objects — navigational dangers.

Apart from safety criteria, an important supplement to them are criteria resulting from the regulations in force and principles of good sea practice: substantial and visible course alteration, sufficiently early performed manoeuvre, recommended turn to starboard. The substantial course alteration is understood as such alteration that will be noticed by the navigators on ships in vicinity. When a dangerous situation occurs (risk of collision) the navigator should take preventive actions appropriately early so that the collision situation will be solved. The regulations recommend turn-to-starboard manoeuvre to solve a collision situation.

Economical criteria are related to the performance of transport function by the ship, mainly the requirements imposed by the shipowner. These are mostly formulated as loss of time, extra distance covered, fuel consumption etc. Acceptable values of these losses may be determined in some cases.

\section{Methods of ship safe trajectorydetermination}

The problem of path choice, more broadly regarded as the determination of object movement trajectory, appears in many fields of human activities (management, control) and is a subject of research in various scientific fields and disciplines (technical or economic sciences), e.g. automation and robotics (manipulators, robots), transport (space, air, road, railway and sea). The effects lead to constantly improved methods and algorithms of object movement trajectory determination. These are, inter alia, optimization methods (dynamic optimization, to a smaller degree static optimization) using mathematical tools of the control theory. Also, suboptimal methods with the tools and algorithms of artificial intelligence, tend to be increasingly used. The application of any of these methods requires their adjustment to specific conditions of the problem to be solved.

The operational choice of path is connected with the determination of a manoeuvre or manoeuvres and its or their parameters assuring safe passing of encountered objects [9]. The above problem may be formulated as the problem of determining 
own ship's course and speed from the range of feasible strategies. The path choice problem can be presented as a problem of static optimization: linear or non-linear programming of searching for own ship's speed vector components, assuring an extreme value of a certain objective function. Consideration of additional criteria, such as distance covered or fuel consumption, leads to the formulation of multicriteria optimization task.

The movement control of a sea-going ship, a multidimensional non-linear dynamic object, requires that multiple decisions be made. These decisions are of dynamic nature and consist in the selection of settings (rudder, propulsion) for safe manoeuvre performance. This type of problem is solved by methods of dynamic optimization. The basic issue of the method is the number of computations, growing exponentially with the number of control stages. Alternatively, we can search for suboptimal solutions by using evolutionary algorithms for the optimization of anticollision manoeuvres in encounter situations [14]. Attempts are made to apply other algorithms, based on heuristics, e.g. ant algorithms [7].

Uncertainties (imprecisions) of goals and constraints in path choice can be accounted for by using systems of fuzzy inference, including systems employing methods of multistage control in a fuzzy environment $[1,6]$.

\section{MULTISTAGE CONTROL}

\section{Multistage control}

One of the standard methods of dynamic optimization is dynamic programming, used in problems of multistage decision making and control. Optimal ship control in terms of preset control quality indicator can be determined by using the Bellman's principle of optimality.

For a given $n$-dimensional space of states $\mathbf{X}=\left\{x_{1}, \ldots x_{n}\right\}$ and $m$-dimensional space of controls $\mathbf{U}=\left\{u_{1}, \ldots u_{m}\right\}$, state transitions in subsequent $k$ stages of control are represented by this function:

$$
\mathrm{f}: \mathbf{X} \times \mathbf{U} \rightarrow \mathbf{X}
$$

such that:

$$
\begin{gathered}
i=0,1,2, \ldots, k-1 \quad x_{t_{i+1}}=\mathrm{f}\left(x_{t_{i}}, u_{t_{i}}\right) \\
t-\text { time }
\end{gathered}
$$


The equations of state transitions may then have this form:

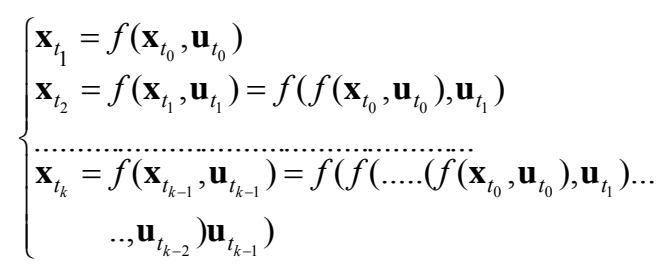

The optimization problem is to find such control function $\mathbf{u}(t)$, defining the optimal trajectory $\mathbf{x}(t)$ that the quality functional $J$ will assume a minimum value:

$$
J(\hat{\mathbf{x}}(t), \hat{\mathbf{u}}(t), t)=\min _{\mathbf{u}(t) \in \mathbf{U}_{0}, \mathbf{x}(t) \in \mathbf{X}_{0}} \int_{t_{0}}^{t_{k}} f_{0}(\mathbf{x}(t), \mathbf{u}(t), t) d t
$$

where:

$f_{0} \quad$ - function of instanteneous losses;

$\mathbf{u}(t) \in \mathbf{U}_{0}$ - set of allowable controls;

$\mathbf{x}(t) \in \mathbf{X}_{0}$ - maximum trajectory space.

The control strategy, determining the optimal trajectory, consists of a series of controls:

$$
\hat{u}=\left(\hat{u}_{t_{o}}, \hat{u}_{t_{1}}, \ldots, \hat{u}_{t_{k-1}}\right)
$$

Generally, the control quality indicator takes account of the safety and economical criteria. Correspondingly, the ship's present position described by the ship's state vector is adopted as the initial condition (point), while the final condition (point) is:

- preset final point of the trajectory (control with the preset final point);

- preset final course, principally the same as the original course.

The above problem can be solved by various methods. The problem of optimal trajectory determination may be effectively solved using the graph theory. We make use of the directed graph properties, i.e. the orientation of edges and direction of arrows indicate the movement direction or sequence of choice. One of the most effective algorithms available for the determination of the shortest path between a pair of nodes is the Dijkstra algorithm [6]. 


\section{Multistage control in a fuzy environment}

The fuzzy environment can be presented as an ordered four $\langle\boldsymbol{G}, \boldsymbol{C}, \boldsymbol{D}, \boldsymbol{U}\rangle$ ( $\boldsymbol{G}$ - fuzzy goal, $\boldsymbol{C}$ - fuzzy constraints, $\boldsymbol{D}$ - fuzzy decision, $\boldsymbol{U}-$ set of decisions). For a given $n$-dimensional space of states $\mathbf{X}=\left\{x_{1}, \ldots x_{n}\right\}$ and $m$-dimensional space of controls $\mathbf{U}=\left\{u_{1}, \ldots u_{m}\right\}$ the fuzzy goal is defined as a fuzzy set $\boldsymbol{G} \subseteq \boldsymbol{U}$ with the membership function $\mu_{G}$ :

$$
\mu_{G}: \boldsymbol{X} \times \boldsymbol{U} \rightarrow[0,1] \in \boldsymbol{R}
$$

and the fuzzy constraint as a fuzzy set $\boldsymbol{C} \subseteq \boldsymbol{U}$ with the membership function $\mu_{C}$ :

$$
\mu_{C}: \boldsymbol{X} \times \boldsymbol{U} \rightarrow[0,1] \in \boldsymbol{R}
$$

The state transitions in subsequent $k$ stages of control are defined by the function (1), (2).

If a decision is made in a fuzzy environment, i.e. with a constraint $\boldsymbol{C}$ and goal $\boldsymbol{G}$, described, respectively, by membership functions $\mu_{C}(x)$ and $\mu_{G}(x)$, the fuzzy decision $\boldsymbol{D}$ is determined from this relationship:

$$
\mu_{D}(x)=\min _{x \in X}\left(\mu_{G}(x), \mu_{C}(x)\right)
$$

It is adopted that an optimal decision is one that maximizes the degree of membership to the set of fuzzy decisions $\boldsymbol{D}$ :

$$
\mu_{D}\left(x^{*}\right)=\max _{x \in X}\left(\mu_{D}(x)\right)
$$

This also refers to a situation where many golas and constraints exist. Then the fuzzy decision is defined as:

$$
\mu_{D}(x)=\mu_{G 1}(x) * \mu_{G 2}(x) * \ldots . . * \mu_{G s}(x) * \mu_{C 1}(x) * \mu_{C 2}(x) * \ldots . . * \mu_{C p}(x)
$$

where:

$p$ - number of goals;

$s$ - number of constraints.

The control process consists in selecting controls $u$ with imposed constraints $\mu_{\mathrm{C}}(x)$, with goals $\mu_{G}(x)$ imposed on the states $x$ in subsequent control stages. As a quality 
indicator of the multistage decision making (control) process for $k$ control stages, this fuzzy decision is adopted:

$$
D\left(x_{t_{0}}\right)=C^{0} * G^{1} * C^{1} * G^{2} * C^{k-1} * G^{k}
$$

described by the membership functions:

$$
\begin{aligned}
\mu_{D}\left(u_{t_{0}}, \ldots, u_{t_{k-1}} \mid x_{t_{0}}\right)= & \mu_{C 0}\left(u_{t_{0}}\right) * \mu_{G 1}\left(x_{t_{1}}\right) * \ldots \\
& * \mu_{C k-1}\left(u_{t_{k-1}}\right) * \mu_{G k}\left(x_{t_{k}}\right)
\end{aligned}
$$

The achieved states $x_{t_{1}}, x_{t_{2}}, \ldots, x_{t_{k}}$ are determined by subsequent use of the state transition equation (3). as follows:

The problem of multistage control in a fuzzy environment is then formulated

$$
\mu_{D}\left(u_{t_{0}}^{*}, \ldots, u_{t_{k-1}}^{*} \mid x_{t_{0}}\right)=\max \left(\mu_{D}\left(u_{t_{0}}, \ldots, u_{t_{k-1}} \mid x_{t_{0}}\right)\right)
$$

The optimal strategy, consequently, has the form of this series of controls $u^{*}$ :

$$
u^{*}=\left(u_{t_{0}}^{*}, u_{t_{1}}^{*}, \ldots, u_{t_{k-1}}^{*}\right)
$$

The following is proposed for the description of fuzzy goal and fuzzy constraint of fuzzy sets described by their respective membership functions:

- goal: safe distance of passing an object (another ship, navigational danger);

- constraint: possibly small 'losses of distance' (shift of the original trajectory).

Another constraint was the requirement of performing the manoeuvre noticeably, i.e. course alteration should be visible, i.e. readily apparent to targets.

Similarly to the case of multistage control, the above problem can be solved by dynamic programming methods, i.e. by the branch and bound method, or by using the graph theory.

\section{RESEARCH}

\section{The scope of research}

The research was aimed at comparing the effectiveness of selected algorithms for ship's safe trajectory determination in encounter situations in a restricted 
area. The worked out solutions were analyzed in respect to safety and the time of finding these solutions, essential for their application in real conditions. The research was done by using computer simulation, based on the developed scenario of a navigational situation. The scenario included moving objects (vessels), nearby land and other stationary navigational dangers (fig. 1).

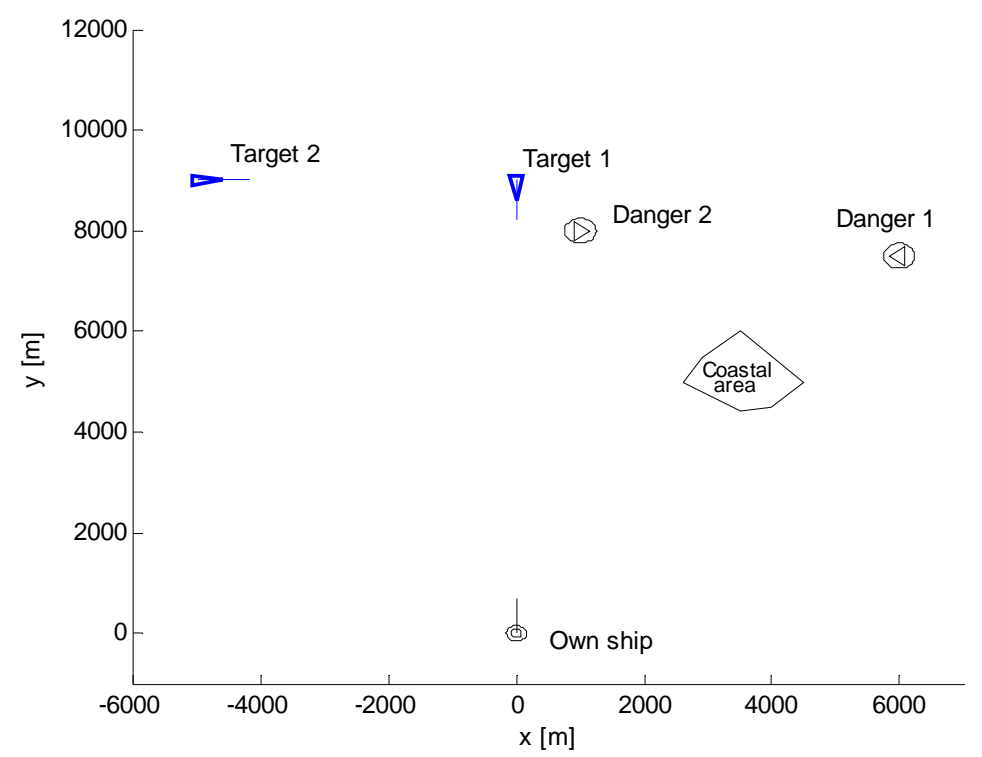

Fig. 1. A scenario of ship encounter in a restricted area [own study]

Algorithms of multistage control and multistage control in a fuzzy environment were examined for a number of variants of goals and constraints and the corresponding criteria:

- multistage control:

- own ship described by its domain; targets described by their contours,

- own ship described by its contour; targets described by their domains,

- all objects (own ship, targets) described by their domains;

- multistage control in a fuzzy environment:

- own ship described by a fuzzy domain; targets described by their contours,

- own ship described by its contour; targets described by their fuzzy domains,

- own ship and targets described by their fuzzy domains.

It was assumed that own ship and two targets included in the scenario are of the same type (table 1). 
Table 1. Ship model [12]

\begin{tabular}{|l|c|}
\hline Ship model & LO-RO ship \\
\hline Ship type & LO-RO \\
\hline Length overall $\left(\mathrm{L}_{\mathrm{c}}\right)[\mathrm{m}]$ & 174.0 \\
\hline Breadth $(\mathrm{B})[\mathrm{m}]$ & 23.0 \\
\hline Draft forward $\left(\mathrm{D}_{\mathrm{A}}\right)$ & 7.5 \\
\hline Speed over water $(\mathrm{SOW})[$ knots $]$ & 16.3 \\
\hline
\end{tabular}

It was assumed for the ships that their domains are elliptical in shape with dimensions given in table 2, where the boundary of the (crisp) domain was adopted as the so called mean boundary, and the boundaries of the fuzzy domain were described by the boundaries of the minimum and maximum domains.

Table 2. Domain boundary dimensions of LO-RO ship [12]

\begin{tabular}{|l|c|c|}
\hline Domain boundary & Length & Width \\
\hline minimum (fuzzy) & $1200[\mathrm{~m}]$ & $675[\mathrm{~m}]$ \\
\hline mean (domain) & $1900[\mathrm{~m}]$ & $955[\mathrm{~m}]$ \\
\hline maximum (fuzzy) & $3670[\mathrm{~m}]$ & $1595[\mathrm{~m}]$ \\
\hline
\end{tabular}

Coastal areas and navigational dangers were simulated. The boundaries of navigational danger domains were adopted as lines joining the points lying at certain distances from these objects: $200 \mathrm{~m}$ (main domain); $200 \mathrm{~m}$ minimum (fuzzy), $400 \mathrm{~m}$ maximum (fuzzy). For the coastline a constant safety zone (domain) was adopted, covering an area up to $500 \mathrm{~m}$ along the land.

In the determination of ship movement trajectory by the method of multistage control in a fuzzy environment also the criteria of minimized shift and noticeable course alteration described by relevant functions of membership to fuzzy sets.

\section{Ship movement trajectories - multistage control}

Simulations were carried out for the mentioned variants of safe trajectory determination using the multistage control method.

The safety criterion in the first variant was own ship's domain. The goal was to safely pass objects (ships, land, navigational dangers) and return to the original course with a minimum shift understood as own ship's deviation from the original trajectory. As the navigation took place in a restricted area, geometrical dimensions of targets were taken into account. To solve the above problem, we have to define our ship domain. Apart from information on the positions and dimensions of land and other navigational dangers available on an $\mathrm{ENC}$, we have to know the positions and geometrical dimensions of targets, obtained, for instance, from the AIS system. It can be assumed 
that this information will be available on our ship. The obtained solution of a collision situation satisfies the safety requirements (fig. 2).
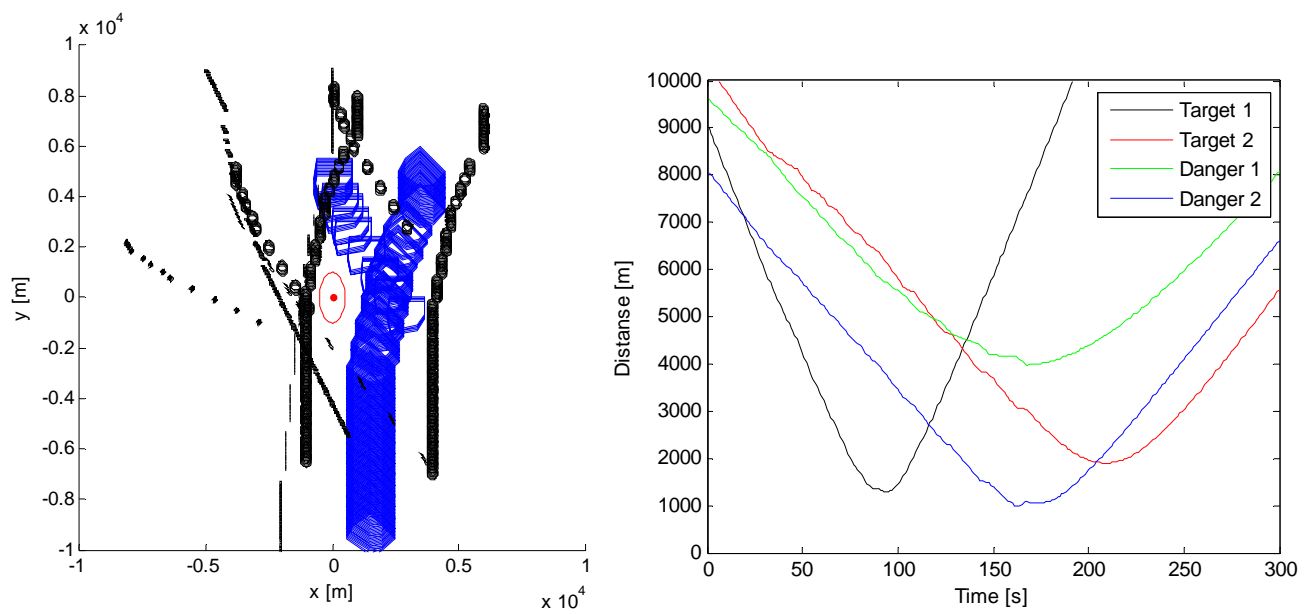

Fig. 2. Target tracks described by contours, relative to own ship described by the domain (variant 1): a) targets tracks; b) distances to targets [own study]

The next variant assumed the domains of targets as the safety criterion, and accounted for the dimensions of our own ship. This means these domains have to be defined. If data on these objects are unavailable or insufficient, the solution, as proposed in literature, can be obtained by assigning a domain like that of own ship to them. Although this approach raises some doubts, it offers wider possibilities of choosing the path or manoeuvre by our ship. The obtained solution of a collision situation satisfies the safety requirements (fig. 3).
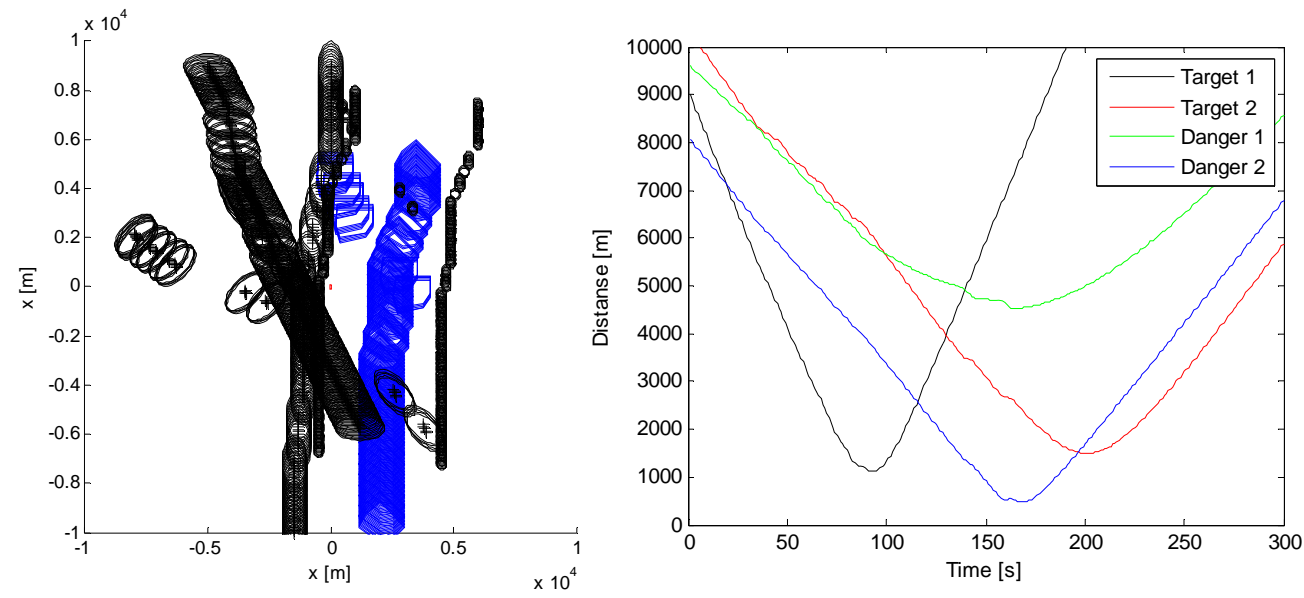

Fig. 3. Target tracks described by domains, relative to own ship described by its contour (variant 2): a) targets tracks; b) distances to targets [own study] 
The third variant includes the domains of all objects into account. It requires, however, that, like in variant 2 , the domains of targets should be defined. The obtained solution, though, guarantees that safe areas will be maintained by all vessels (fig. 4). The obtained solution of a collision situation satisfies the safety requirements (fig. 5).

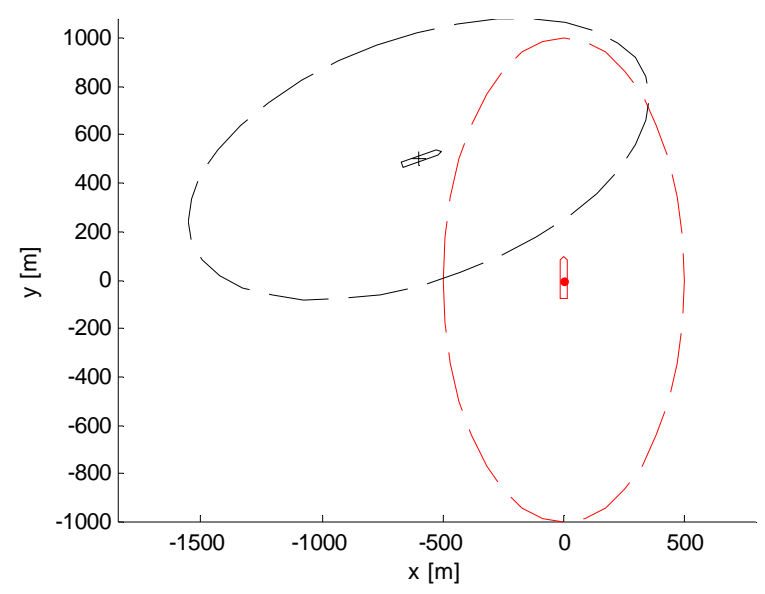

Fig. 4. Variant 3 of the algorithm

for the choice of path: domains of encountering vessels [own study]
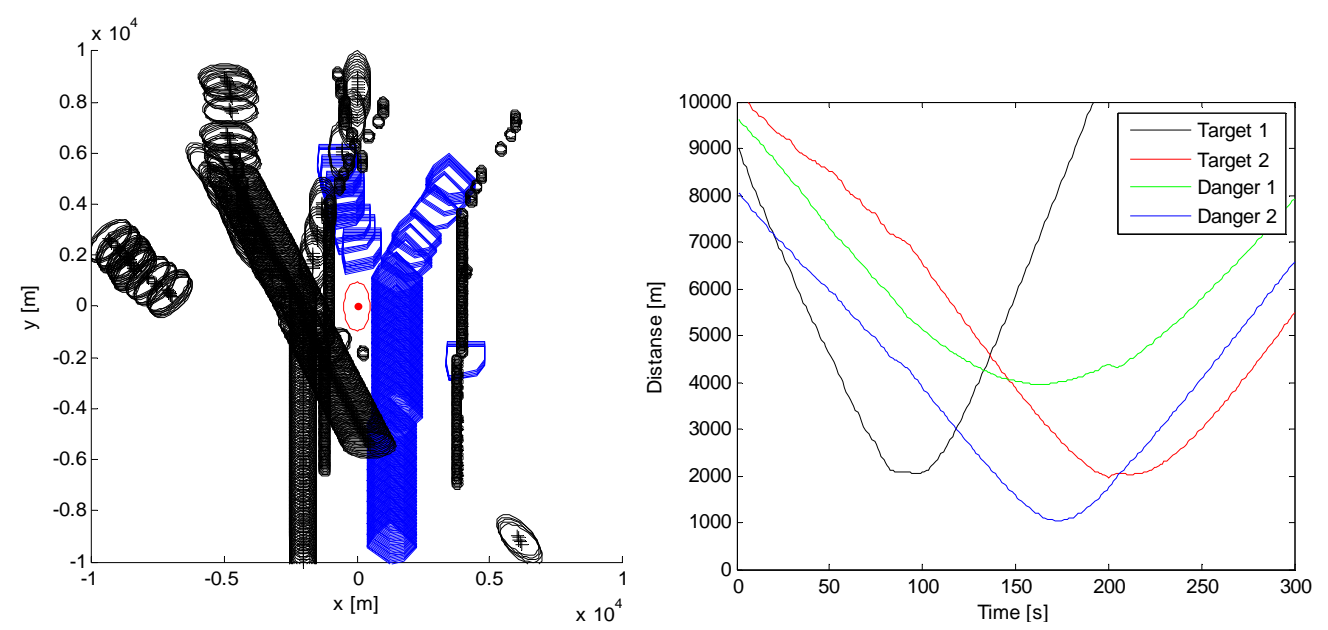

Fig. 5. Target tracks described by domains, relative to own ship described by the domain (variant 3): a) targets tracks; b) distances to targets [own study]

\section{Ship movement trajectories - multistage fuzzy control}

Since the human in certain situations tends to distinguish a number of zones, described linguistically as safe, less safe, dangerous etc., it was justified to consider 
variants $3-6$ of the choice of path using the method of multistage control in a fuzzy environment and to introduce the fuzzy domain as the safety criterion. The human being (navigator), depending on the situation, attempts to keep a selected zone clear of other objects. Similarly, in the ship conduct process, depending on the situation, the navigator tries to maintain an area around his/her ship at a predetermined level of navigational danger (safety) that is to be clear of other objects.

In variant 4 the own ship fuzzy domain, needed to solve the above problem, was adopted as the safety criterion. Like in variant 1 , we need information on the positions and dimensions of land and other navigational dangers available on an ENC, and similar data on targets, obtained from, e.g. the AIS system. The criterion of ship fuzzy domain allows to depart from the crisp conditions for passing targets by introducing an specific range of tolerance. This makes possible the determination of a trajectory in situations where no solution is generated with the ship domain criterion used. The obtained solution of a collision situation satisfies the safety requirements (fig. 6).
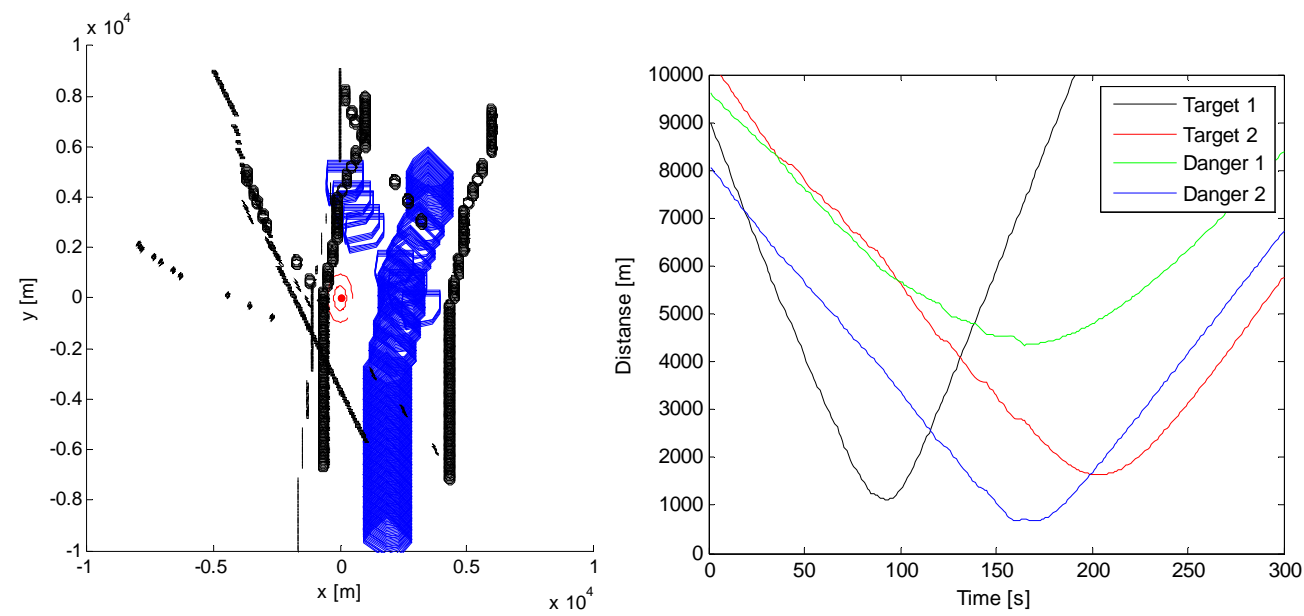

Fig. 6. Target tracks described by contours, relative to own ship described by its fuzzy domain (variant 4): a) targets tracks; b) distances to targets [own study]

In variant 5 fuzzy domains of targets were adopted as the safety criterion, and the dimensions of own ship were taken into account. Similarly to variant 2 , this means these domains had to be defined, which can be done by attributing them predetermined standard fuzzy domains, characteristic of a given ship type. In another method we attribute our own domain to targets. The obtained solution of a collision situation satisfies the safety requirements (fig. 7). 

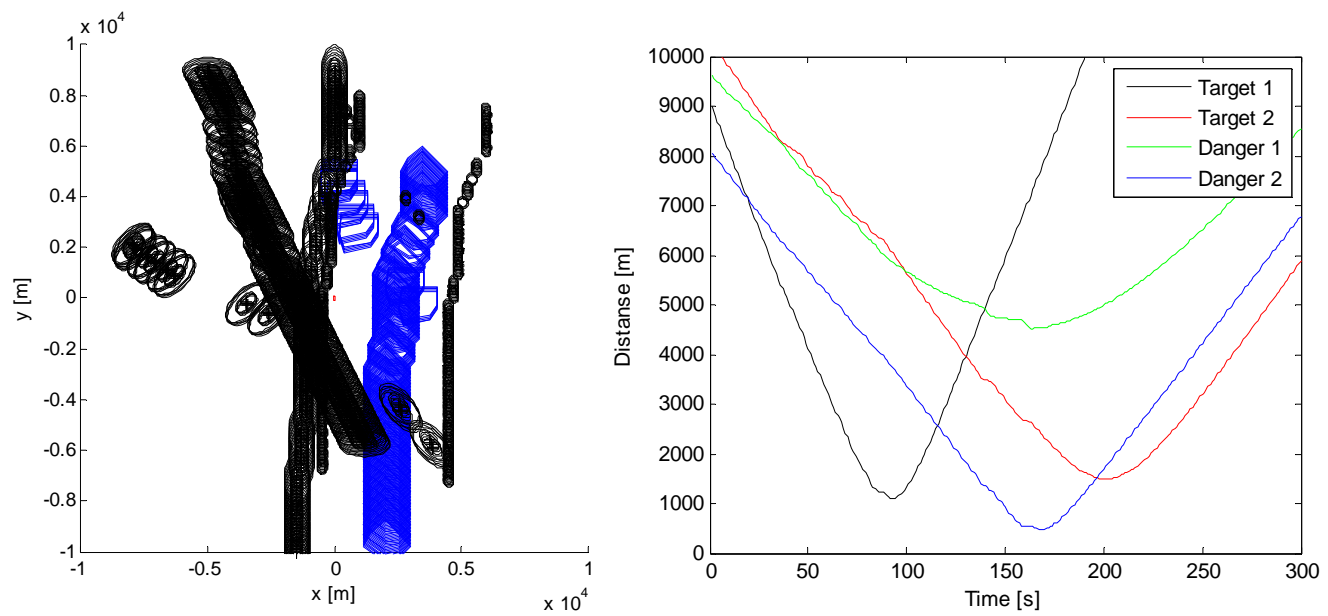

Fig. 7. Target tracks described by fuzzy domains, relative to own ship described by its contour (variant 5): a) targets tracks; b) distances to targets [own study]

Variant 6 takes into account fuzzy domains of all ships. Like in variant 5, fuzzy domains of targets have to be defined. The obtained solution, however, guarantees that all ships take account of safe areas, thus it satisfies the safety requirements (fig. 8).
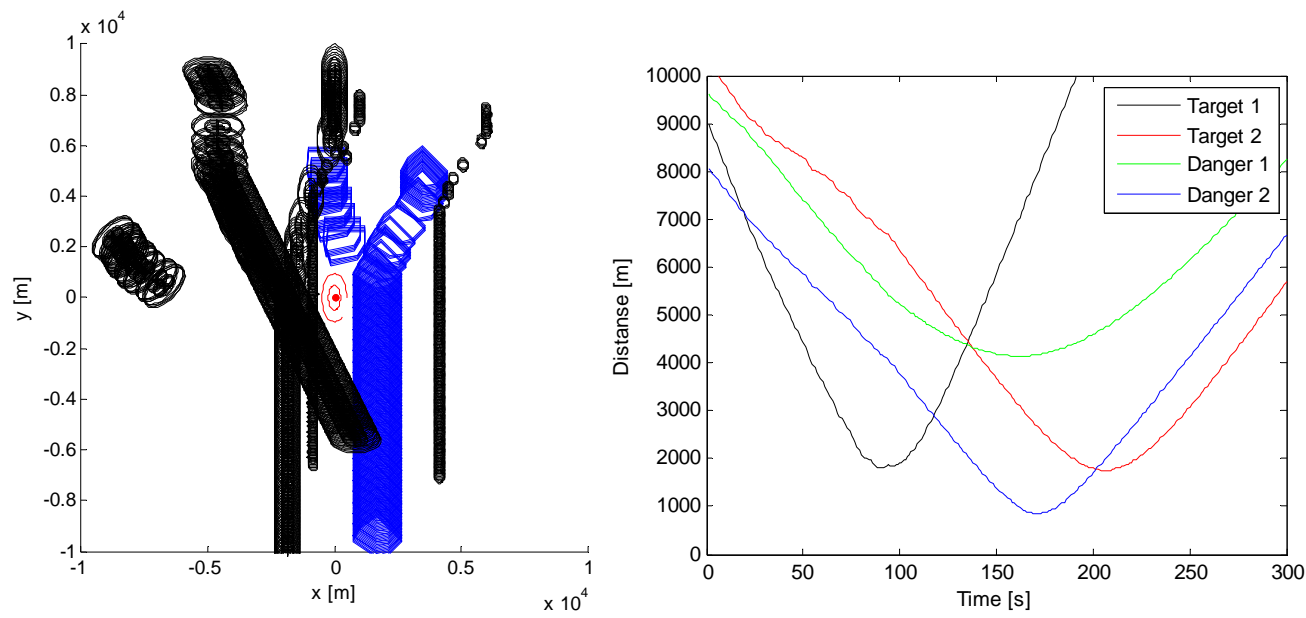

Fig. 8. Target tracks described by fuzzy domains, relative to own ship described by its fuzzy domain (variant 6): a) targets tracks; b) distances to targets [own study]

\section{Analysis of the results}

Figure 9 presents determined trajectories of own ship movement for the examined variants of path choice. All proposed solutions satisfy the conditions of safe 
navigation. As it was observed previously, solutions for which own ship was described by its contour are characterized by a later start of the manoeuvre and smaller shift from the original trajectory.

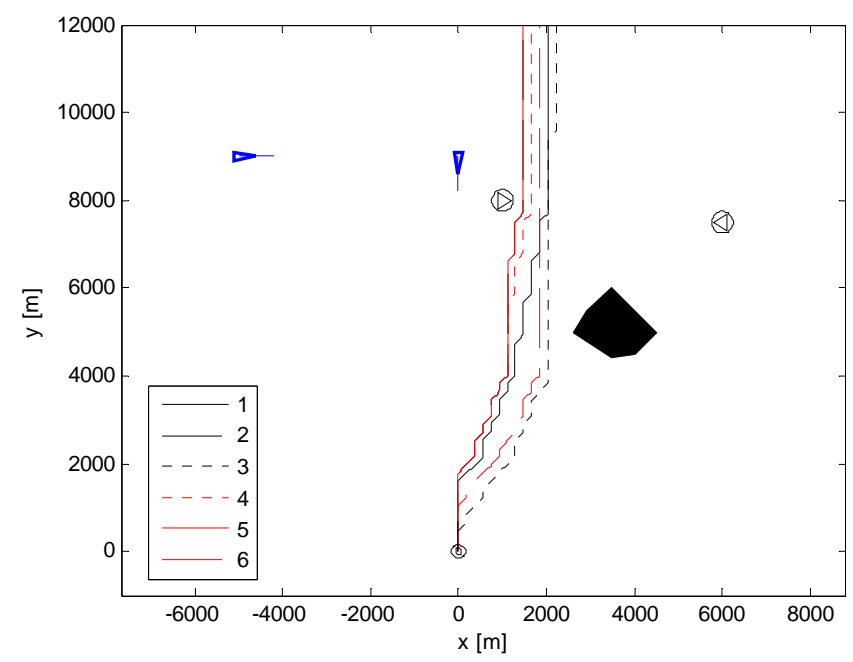

Fig. 9. Trajectories of own ship movement for several variants of path choice [own study]

Detailed results of the simulations are given in table 3 . The greatest distances of passing other targets by own ship were found in variants $1-3$. This confirms a greater flexibility in path determination offered by variants of multistage control in a fuzzy environment.

The values of computation times for each variant allows to draw conclusions on their possible use in real conditions (on line) to solve more complex navigational situations as well.

Table 3. Variants of the trajectory choice - characteristics [own study]

\begin{tabular}{|c|c|c|c|r|r|c|c|}
\hline Variant & $\begin{array}{c}\text { Min } \\
\text { distance } \\
\text { target 1 } \\
{[\mathrm{m}]}\end{array}$ & $\begin{array}{c}\text { Min } \\
\text { distance } \\
\text { target 2 } \\
{[\mathrm{m}]}\end{array}$ & $\begin{array}{c}\text { Min } \\
\text { distance } \\
\text { danger 1 } \\
{[\mathrm{m}]}\end{array}$ & $\begin{array}{c}\text { Min } \\
\text { distance } \\
\text { danger 2 } \\
{[\mathrm{m}]}\end{array}$ & $\begin{array}{c}\text { Min } \\
\text { distance } \\
\text { to land } \\
{[\mathrm{m}]}\end{array}$ & $\begin{array}{c}\text { Shift } \\
{[\mathrm{m}]}\end{array}$ & $\begin{array}{c}\text { Computation } \\
\text { time } \\
{[\mathrm{s}]}\end{array}$ \\
\hline 1 & 1296.40 & 1889.04 & 3963.28 & 981.56 & 1118.4 & 2037.2 & 0.50 \\
\hline 2 & 1111.20 & 1500.12 & 4518.88 & 481.52 & 1488.8 & 1481.6 & 0.48 \\
\hline 3 & 2037.20 & 1963.12 & 3963.28 & 1037.12 & 562.8 & 2222.4 & 0.91 \\
\hline 4 & 1111.20 & 1629.76 & 4333.68 & 666.72 & 1488.8 & 1666.8 & 0.26 \\
\hline 5 & 1111.20 & 1500.12 & 4518.88 & 481.52 & 1488.8 & 1481.6 & 0.46 \\
\hline 6 & 1796.44 & 1759.40 & 4148.48 & 851.92 & 748.0 & 1852.0 & 0.64 \\
\hline
\end{tabular}




\section{SUMMARY}

The article deals with the problem of safe trajectory determination for a ship encoutering other ships in a restricted area. Seven variants of path optimization were considered, using both crisp criteria (ship domain) and fuzzy criteria (ship fuzzy domain). Parameters of the area, including land and navigational dangers, were taken into account. The results for a selected scenarion were presented.

The obtained results satisfy the criteria of safe navigation.

The results confirm that the examined variants of the path optimization can also be used in real conditions (on line) on board a sea-going vessel for solving more complex navigational situations than the simulated one.

The choice of a variant will depend, inter alia, on the availability of defined domains (own ship, targets, navigational dangers).

\section{REFERENCES}

[1] Bellman R. E., Zadeh L. A., Decision making in a fuzzy environment, Management Science, 1970, No. 17.

[2] COLREGs 1972, Convention on the international regulations for preventing collisions at sea, International Maritime Organization.

[3] Deo N., The Theory of Graphs and its Application in Technology and Computer Science (in Polish), PWN, Warszawa 1980.

[4] Fujii Y., Tanaka K., Traffic capacity, Journal of Navigation, 1971, No. 24, pp. 543-552.

[5] Goodwin E. M., A statistical study of ship domain, Journal of Navigation, 1975, No 28, pp. 328-341.

[6] Kacprzyk J., Multi-stage fuzzy control (in Polish), WNT, Warszawa 2001.

[7] Mąka M., Dramski M., The choice of ship's safe route in a restricted area with the use of quadtrees for a simplified ant algorithm, XIV International Scientific and Technical Conference on Marine Traffic Engineering MTE2011, Świnoujście 2011, pp. 319-328.

[8] Pietrzykowski Z., Ship's fuzzy domain - a criterion for navigational safety in narrow fairways, The Journal of Navigation, 2008, Vol. 61, The Royal Institute of Navigation, Cambridge, pp. 501-514.

[9] Pietrzykowski Z., Fuzzy Control in Solving collision Situations at Sea, Computational Intelligence: Methods and Applications, eds. L. Rutkowski, R. Tadeusiewicz, L. A. Zadeh, J. Żurada, Akademicka Oficyna Wydawnicza EXIT, Warszawa 2008, pp. 103-111. 
[10] Pietrzykowski Z., Uriasz J., The ship domain — a criterion of navigational safety assessment in an open sea area, The Journal of Navigation, 2009, Vol. 62, The Royal Institute of Navigation, Cambridge, pp. 93-108.

[11] Pietrzykowski Z., Modelling of Decision Processes in Sea-Going Ship Movement (in Polish), Control, Studies, 2004, No. 43, Maritime University of Szczecin.

[12] Pietrzykowski Z., Wielgosz M., Siemianowicz M., Simulation research on the ship domain in the restricted area, Proc. of $14^{\text {th }}$ International Marine Traffic Engineering, Świnoujście 2011, pp. 397-406.

[13] Śmierzchalski R., Weintrit A., Domains of navigational objects as an aid to route planing in collision situation at sea (in Polish), Proc. of $3^{\text {rd }}$ Navigational Symposium, Gdynia, 1999, I, pp. 265-279.

[14] Śmierzchalski R., Michalewicz Z., Modelling of a ship trajectory in collision situations at sea by evolutionary algorithm, IEEE Transaction on Evolutionaty Computation, 2000, Vol. 4, No. 3, pp. 227-244.

[15] Wang N., Meng X., Xu Q., Wang Z., A unified analytical framework for ship domains, Journal of Navigation, 2009, No. 24, Vol. 62, pp. 643-655.

[16] Zhao J, Wu Z., Wang F., Comments of ship domains, Journal of Navigation, 1993, No. 46, pp. 422-436.

Received May 2012

Reviewed October 2012 